\title{
Teaching writing online: technology means more writing, more interactivity
}

\section{Tzipora Rakedzon}

Technion - Israel Institute of Technology, Israel

Keywords: Covid-19; academic writing; online learning; STEM education.

\section{The challenge}

Writing requires individual work, but it can also benefit from group interaction and instruction (Hanson, Loose and Reveles, 2020). Therefore, to support our STEM (Science, Technology, Engineering and Mathematics) PhD students, the graduate writing course is compulsory. As writing should be learned not just by listening but by doing, our course had a workshop structure, i.e., an interactive lecture with in-class writing exercises. This allowed students to consult with the lecturer or other students in real-time. However, in March 2020, the Covid-19 pandemic forced the university, one week before our spring semester began, to go online. The main challenge became - how could this interactive workshop format be preserved online?

The first feeling was panic: where do I start; how should I prepare? As a lecturer and the head of the academic writing program at my university, I had wanted to create my own online materials for our graduate STEM academic writing course. However, I had never found the time, and now I needed such materials right away. At first, I let the idea sink in - even though time was short. My plan was to create material for my PhD students that (a) could be used in future semesters and (b) would create an interactive online writing experience: after all, we did not know how long the pandemic would last.

\section{The response}


Planning the lectures: at that point, I decided that for each of the 13 lectures, I would record key parts of the lessons in 10-20 minute videos. I created 20 videos, with lessons having one or two videos with a total viewing time of no more than 20 minutes in a one-hour class. Moreover, all lessons were recorded so they could be watched again.

Then, I was able to organise my weekly live lessons according to my then five-stage final plan:

- Live group discussion.

- Send students to watch the video.

- Give students a task(s), follow their progress on the shared file, and continue only when most students finished.

- Return to plenary to review the task live.

- Continue with an online live lecture.

This plan was designed to fulfil my main goal of keeping students active, allowing them to work on in-class exercises at their own pace (Lapitan Jr et al., 2021), and easing the students' experience by using a consistent lesson format.

The semester was crazy, but this format seemed to be paying off. I could tell students were doing well just by seeing their work on the shared file on a weekly basis. In the regular classroom, classwork and homework exercises are reviewed together during the lesson meaning only a small handful of students would share answers. Here, every student shared answers and received feedback.

Assessing the lectures: I surveyed the students mid-semester, and results were similar to previous research (e.g., Schlenz et al., 2020; Nguyen et al., 2021): of the 58 students who answered, almost $45 \%$ would prefer to have this writing course online and $33 \%$ would prefer a combination of in-class and online lectures. This showed the positive impact of the online course, most likely due to two factors: the amount of individual writing produced and 
assessed during the online lecture and the age of the students. PhD students are older and more disciplined; many were young parents who benefited from this flexibility of remote study.

Students also appreciated the interactivity and convenience of the online lesson (e.g., Harris and Martin, 2012). Almost $80 \%$ of students said they liked the combination of pre-recorded videos with online live discussion: 'The option to have recorded videos I can watch in my free time, or several times'; 'The recorded videos are very focused on the main topics, while the online discussions help in general understanding and expansion of the theme'. Comments also showed the success of the shared file in engaging students in weekly exercises, as students liked 'the progress I see in my writing each week' and 'the online file ... so we can learn from others' mistakes'.

Beyond insights on exactly what worked, the survey also showed the weaknesses of the online writing course. The most frequent criticism can be summarised by: 'there are many different platforms used during class, it makes confusion and stress'. This was partially solved simply by waiting for students to undergo the 'learning curve' in using online platforms.

\section{Recommendations}

Looking back on the past four online semesters, I think there are several lessons to be learned. Firstly, listen to your students about the use of technology. Their suggestion about too many platforms was correct; however, I have not yet found one platform to suit all my needs. I do recommend choosing user-friendly platforms and keeping the number to a minimum. I also noticed that as time progressed, the various online formats became easier. In general, both using and choosing the appropriate technology is an ongoing challenge for both students and instructors (Lapitan Jr et al., 2021).

Secondly, try to provide as much interaction as possible (Nguyen et al., 2021). Writing lessons require actual writing and feedback - which is easier online. This may include, for example, mixing shared files, live discussions, and smaller group discussions in breakout rooms. 
Thirdly, listen and share with your staff. I allowed my staff, the wonderful lecturers who teach the academic writing course with me, to tackle the online format as they chose. This means I offered support and materials, but I did not pressure them to change. Consequently, in the first semester some lecturers simply gave the same in-class lecture on Zoom. Subsequently this changed: several teachers made their own videos, some used my videos, and some used shared files. The bottom line is: share material, and leave room for training, patience, individual expression, and preference (Lapitan Jr et al., 2021).

Overall, going forward it would be ideal to have a hybrid format of the writing course, with some lessons online and others in-class. Another option could be to offer exclusively online or in-class groups. I believe both formats should try and keep the main benefits of the online course: shared files, allowing students to write more and receive more feedback, and use of videos, enabling repeated viewing. In the end, it may sound strange, but I am thankful that I had the opportunity that was forced upon us to develop the online version of the writing course.

\section{References}

Hanson, J., Loose, W. and Reveles, U. (2020) 'A qualitative case study of all-but-dissertation students at risk for dissertation noncompletion: a new model for supporting candidates to doctoral completion', Journal of College Student Retention: Research, Theory \& Practice. https://doi.org/10.1177/1521025120910714.

Harris, H. S. and Martin, E. W. (2012), 'Student motivations for choosing online classes', International Journal for the Scholarship of Teaching and Learning, 6(2). https://doi.org/10.20429/ijsotl.2012.060211.

Lapitan Jr, L. D., Tiangco, C. E., Sumalinog, D. A. G., Sabarillo, N. S. and Diaz, J. M. (2021), 'An effective blended online teaching and learning strategy during the COVID-19 
pandemic', Education for Chemical Engineers, 35, pp.116-131.

https://doi.org/10.1016/j.ece.2021.01.012.

Nguyen, T., Netto, C. L., Wilkins, J. F., Bröker, P., Vargas, E. E., Sealfon, C. D., Puthipiroj, P., Li, K. S., Bowler, J. E., Hinson, H. R., Pujar, M. and Stein, G. M. (2021) 'Insights into students' experiences and perceptions of remote learning methods: from the COVID19 pandemic to best practice for the future', Frontiers in Education, (6), p.91. https://doi.org/10.3389/feduc.2021.647986.

Schlenz, M. A., Schmidt, A., Wöstmann, B., Krämer, N. and Schulz-Weidner, N. (2020) 'Students' and lecturers' perspective on the implementation of online learning in dental education due to SARS-CoV-2 (COVID-19): a cross-sectional study', BMC Medical Education, 20(1), pp.1-7. https://doi.org/10.1186/s12909-020-02266-3.

\section{Author details}

Tzipora Rakedzon serves as the coordinator and a lecturer of Graduate Academic Writing in the Department of Humanities at the Technion - Israel Institute of Technology. She has been teaching a variety of writing and communication courses for over 20 years. Tzipora received her $\mathrm{PhD}$ at the Technion in science communication at the Department of Education in Technology and Science. She is also a lecturer and the coordinator of the English Programme at the Guangdong Technion in China. Her research deals with assessing written skills in academic and popular science writing. 